\section{How does the Government of Indonesia empower SMEs? An analysis of the social cognition found in newspapers}

Analysis of social cognition

\author{
Jenri MP Panjaitan
}

Department of Leadership and Policy Innovation, Gadjah Mada University, Yogyakarta, Indonesia, and

Rudi Prasetya Timur and Sumiyana Sumiyana

Department of Accounting, Faculty of Economics and Business, Gadjah Mada

University, Yogyakarta, Indonesia

\begin{abstract}
Purpose - This study aims to acknowledge that most Indonesian small and medium enterprises (SMEs) experience slow growth. It highlighted that this sluggishness is because of some falsification of Indonesia's ecological psychology. It focuses on investigating the situated cognition that probably supports this falsification, such as affordance, a community of practice, embodiment and the legitimacy of peripheral participation situated cognition and social intelligence theories.

Design/methodology/approach - This study obtained data from published newspapers between October 2016 and February 2019. The authors used the Waikato Environment for Knowledge Analysis and the J48 C.45 algorithm. The authors analyzed the data using the emergence of news probability for both the Government of Indonesia (GoI) and Indonesian society and the situated cognition concerning the improvement of the SMEs. The authors inferred ecological psychology from these published newspapers in Indonesia that the engaged actions were still suppressed, in comparison with being and doing.

Findings - This study contributes to the innovation and leadership policies of the SMEs' managerial systems and the GoI. After this study identified the backward-looking practices, which the GoI and the people of Indonesia held, this study recommended some policies to help create a forward-looking orientation. The second one is also a policy for the GoI, which needs to reduce the discrepancy between the signified and the signifier, as recommended by the structuralist theory. The last one is suggested by the social learning theory; policies are needed that relate to developing the SMEs' beliefs, attitudes and behavior. It means that the GoI should prepare the required social contexts, which are in motoric production and reinforcement. Explicitly, the authors argue that the GoI facilitates SMEs by emphasizing the internal learning process.
\end{abstract}

Research limitations/implications - The authors present some possibilities for the limitations of this research. The authors took into account that this study assumes the SMEs are all the same, without industrial clustering. It considers that the need for social learning and social cognition by the unclustered industries is equal. Second, the authors acknowledge that Indonesia is an emerging country, and its economic structure has three levels of contributors; the companies listed on the Indonesian Stock Exchange, then the SMEs and the lowest level is the underground economy. Third, the authors did not distinguish the levels of success for the

(C) Jenri MP Panjaitan, Rudi Prasetya Timur and Sumiyana Sumiyana. Published by Emerald Publishing Limited. This article is published under the Creative Commons Attribution (CC BY 4.0) licence. Anyone may reproduce, distribute, translate and create derivative works of this article (for both commercial and non-commercial purposes), subject to full attribution to the original publication and authors. The full terms of this licence may be seen at http://creativecommons.org/licences/by/4.0/ legalcode

JEL classification - L16, M20, O31, O43

Received 12 April 2020 Revised 3 July 2020 Accepted 6 July 2020

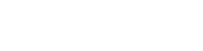


empowerment programs that are conducted by either the GoI or the local governments. This study recognizes that the authors did not measure success levels. It means that the authors only focused on the knowledge content.

Practical implications - From these pieces of evidence, this study constructed its strategies. The authors offer three kinds of policies. The first is the submission of special allocation funds from which the GoI and local governments develop their budgets for the SMEs' social learning and social cognition. The second is the development of social learning and social cognition's curricula for both the SMEs' owners and executive officers. The third is the need for a national knowledge repository for all the Indonesian SMEs. This repository is used for the dissemination of knowledge.

Originality/value - This study raises argumental novelties with some of the critical reasoning. First, the authors argue that the sluggishness of the Indonesian SMEs is because of some fallacies in their social cognition. This social cognition is derived from the cultural knowledge that the GoI and people of Indonesia disclosed in the newspapers. This study shows the falsifications from the three main perspectives of the structuration, structuralist and social learning theories. Second, this study can elaborate on the causal factor for the sluggishness of Indonesia's SMEs, which can be explained by philosophical science, especially its fallacies (Hundleby, 2010; Magnus and Callender, 2004). The authors expand the causal factors for each gap in every theory, which determined the SMEs' sluggishness through the identification of inconsistencies in each dimension of their structuration, structuralism and social learning. This study focused on the fallacy of philosophical science that explains the misconceptions about the SMEs' improvement because of faulty reasoning, which causes the wrong moves to be made in the future (Dorr, 2017; Pielke, 1999).

Keywords Engagement, Empowerment, Small and medium enterprise, Situated cognition, Social cognition, Peripheral participation

Paper type Research paper

\section{Introduction}

This study starts with the sluggish growth of most Indonesian small and medium enterprises (SMEs), although their contribution to domestic production is high (approximately $68.23 \%$ for the past three years). It then investigates the phenomena that caused problems for Indonesian SMEs over the past decade. It raises questions about the form of social cognition that the Government of Indonesia (GoI) and the Indonesian people disclose to printed newspapers. It means that this study inferred Indonesian people learning from their social occurrences (Bandura and Walters, 1977; Proctor and Niemeyer, 2020), situated cognition (Brown et al., 1989; Clancey, 1997) and social intelligence (Kihlstrom and Cantor, 1989, 2000; Thorndike, 1920; Vernon, 1933) theories. This inference would show the historical, social cognition of Indonesian people about SMEs in the country. In other words, this study diagnoses what pieces of social cognition occurred in Indonesian society, which could leverage these SMEs to enlarge and improve their businesses. It then continues to develop some recommendations, which could be taken into account by both the GoI to drive the improvement and growth of the SMEs.

This research raises argumental novelties with some of the critical reasoning below. First, the authors argue that the sluggishness of the Indonesian SMEs is because of some fallacies in their social cognition. This study inferred from the study by Panjaitan et al. (2020) that the Gol's policies could not empower these SMEs to increase their business level. It took into account that all the policies were not related to social cognition and networks, which are used to transform Indonesia's SMEs, so they are ready for change. This social cognition is derived from the cultural knowledge that the GoI discloses in the newspapers. This study shows the falsifications from the three main perspectives of the structuration, structuralist and social learning theories. Meanwhile, the study bundled the three approaches listed above, which are used to explain the SMEs' sluggishness, with the theories of situated cognition, social intelligence and engagement. From the structuration 
and structuralist theories, this research split two concepts, which are used to examine the phenomena. They are structure-in-use and structural-potential (Bryant and Jary, 2014; Giddens, 1991). These concepts measure the GoI and how it used its resources and cultural knowledge to improve the SMEs (Cao et al., 2009; Giddens, 1991; Stones, 2005). From the perspective of the structuralist theory, this research differentiates between the signified and the signifier (Balzer and Moulines, 2011; Koslow, 2005). It also examined the unbalanced use of these concepts, which highlighted the fallacy of the SMEs' suppression. When the use of structure-in-use and structural-potential is equivalent, the SMEs could progress if they would work together. We, moreover, argue that the use of the signified lower than the signifier based on the structuralist theory would also support the SMEs' enhancements.

From the perspective of the social learning theory, this study observes the cognitive processes of the Indonesian SMEs in their efforts to achieve broad social contexts (Bandura and Walters, 1977; Pinho et al., 2019; Tu, 2000), through their beliefs, attitudes and behavior. In the elaboration process, this study investigates these phenomena using three theories, which are situated cognition, social intelligence and engagement. These theories are used to diagnose the sluggishness phenomenon. The situated cognition theory highlights the social contexts that the GoI uses for storing and retrieving conceptual knowledge (Brown et al., 1989). The social intelligence theory is concerned with evolving social beliefs, attitudes and behavior (Baron-Cohen et al., 1999; Brown et al., 1989; Kihlstrom and Cantor, 1989, 2000). It means that social intelligence could explain the development process of the GoI in capitalizing on their experiences (Earley and Ang, 2003; Katjasungkana and Wieringa, 2003). The last is the engagement theory that could provide pieces of evidence, especially about what sort of effort the GoI has made to improve the SMEs. This engagement theory focuses on the GoI what they are trying to be, or do or how they act (Braithwaite and Schrodt, 2014; Ernstson et al., 2014; Loveridge, 2013).

Second, this study can elaborate on the causal factor for the sluggishness of Indonesia's SMEs, which can be explained by philosophical science, especially its fallacies (Hundleby, 2010; Magnus and Callender, 2004). The authors expand the causal factors for each gap in every theory, which determined the SMEs' sluggishness through the identification of inconsistencies in each dimension of their structuration, structuralism and social learning. This study focused on the fallacy of philosophical science that explains the misconceptions about the SMEs' improvement because of faulty reasoning, which causes the wrong moves to be made in the future (Dorr, 2017; Pielke, 1999). On the other hand, it also explains the fallacies believed by the GoI, which has become common cultural knowledge (Bandura and Walters, 1977; Cao et al., 2009; Giddens, 1991). The commonly cultural knowledge, however, did not guarantee the success of the programs and planned to enhance the SMEs. This study finally discovers and then combines all the causal factors into a recommendation, which will probably rearrange social cognition in the future. It means that this study provides a forward-looking orientation to empower Indonesian SMEs.

This study collected data from six newspapers from October 2016 to February 2020. It succeeded in obtaining 1,354 articles. These newspapers were Business Indonesia, The Jakarta Post, Kompas, Kontan, Tempo and Warta Ekonomi. We searched for the data using keywords such as SME, Ministry of Cooperation and SME, enlargement, improvement, exports, readiness, change and all the other words relating to the SMEs' businesses. All the data were analyzed by the Waikato Environment for Knowledge Analysis (WEKA) and the J48 algorithm (Apté and Weiss, 1997; Witten et al., 2011). The researchers, therefore, used this algorithm to bring up statistical calculations for the data pattern of social cognition, which they used to configure a decision tree (Apté and Weiss, 1997; Witten et al., 2011). In this analysis, we used the ten-fold cross-validation test. This study placed the first leaf node 
JEEE 13,5

with structuration in the class that is used by researchers to analyze the formation of data patterns.

This study contributes to the innovation and leadership policies of the SMEs' managerial systems and the GoI. After this study identified the backward-looking practices (Dobson and Khatri, 2000), which the GoI held, this study recommended some policies to help create a forward-looking orientation (Crespy and Vanheuverzwijn, 2019). The first policy is a recommendation for the GoI to reduce the lag between the structure-in-use and the structural-potential, which the structuration theory suggests (Bryant and Jary, 2014). It would probably be a repository for knowledge of the social cognition that is used to enhance the inter-learning systems of the SMEs' executive officers and allow them to anticipate future uncertainties (Contractor and Monge, 2002). The second one is also a policy for the GoI, which needs to reduce the discrepancy between the signified and the signifier, as recommended by the structuralist theory (Balzer and Moulines, 2011; Koslow, 2005). Based on the structuralist theory, the authors argue that the GoI has to create a policy for a prospective economy for the SMEs to operate nationally. The last one is suggested by the social learning theory (Herrmann et al., 2007; van Schaik and Burkart, 2011); policies are needed that relate to developing the SMEs' beliefs, attitudes and behavior. It means that the GoI should prepare the required social contexts, which are in motoric production and reinforcement. Explicitly, the authors argue that the GoI facilitates SMEs by emphasizing the internal learning process. Furthermore, we recommend a complementary policy to this learning, which the GoI has to service all these SMEs with the dashboard for their knowledge sharing.

All these policies can be understood by applying the three theories that have been considered previously. Based on the situated cognition theory, the authors argue that the GoI presents the functional contextualism for the SMEs (Brown et al., 1989; Clancey, 1997). We furthermore conjecture the need for awareness in the dynamic learning process and the SME community's development. Using the social intelligence theory, the GoI should educate the SMEs about the organizational and social knowledge of social change (Ascalon et al., 2008; Boudreaux et al., 2019; Panjaitan et al., 2020; Wang et al., 2019). This study raises the need for social complexity to be understood by the Indonesian SMEs' executive officers, to enhance their competitive readiness. Competitive readiness makes it necessary for the Indonesian SMEs to improve their organizational skills and to develop the power to change (Ford et al., 2015a; Ross and Pierce, 2000; Wang et al., 2019). However, we raise the need for the Indonesian SMEs' to show their commitment and optimism when facing future uncertainty, because of Indonesia's status as an emerging country. This study reaccentuates the policy derived from the engagement theory, which suggested the process to achieve the highest stage of "acting" (Ernstson et al., 2014; Ford et al., 2015a; Panjaitan et al., 2020). In other words, the GoI should use an enhancement strategy for the SMEs, while leaving behind being and doing, but it should be for acting only. It means that this study emphasizes that the increasing national products that are dominated by the SMEs are responsible for the GoI.

The remainder of this paper is structured as follows. Section 2 discusses the theoretical backgrounds, which are the theories of structuration, structuralism and social learning. The authors split the social learning theory using detailed explanations of the situated cognition, intelligence and engagement theories. In this section, the study develops the research proposition. Section 3 presents the research method. The analysis of the contents of all the published newspapers listed previously is used to capture Indonesian social cognition. It is usually found in the cultural knowledge of the GoI. The analytical results of all the materials dealing with social cognition are presented in Section 4. In this section, the authors explain 
the loading contents for Indonesian regulators to facilitate, control and regulate Indonesian SMEs. Section 5 summarizes the study's conclusion, limitations and implications.

\section{Theoretical background and research proposition}

\section{Structuration theory}

Stones (2005) explains that the structuration theory determines the junction of critical social insights that build a stronger society. The structuration theory is used in this study to map the structural cognition in a community that influences conception, implementation and acceptance (Giddens, 1991; Stones, 2005). This study argues that social structuration, as the embodiment of cultural knowledge and resources, is embedded in the cognitive memory of agents. These agents are newspaper readers who usually take social action (Bryant and Jary, 2014; Giddens, 1991; Stones, 2005). The structuration theory contains two structures: "structure-in-use" and "structural-potential." Structure-in-use means an understanding of the implemented and accepted social insights. Structural-potential, meanwhile, implies the ecological psychology of new insights' conceptions from the news. This study uses these two concepts to measure how the GoI has used its cultural resources and knowledge to improve the SMEs' organizational performance (Bryant and Jary, 2014; Sinclaire and Vogus, 2011).

The structuration theory has been transformed into an adaptive structuration theory that describes individuals or communities that have a system, method or procedure for adopting multiple environments or technologies (Cao et al., 2009; DeSanctis and Poole, 1994; Poole and Desanctis, 1990; Scott Poole and DeSanctis, 1992). Adaptive structuration describes the social structure of groups affected by the use of information technology and its evolution (Cao et al., 2009; Furumo and Melcher, 2006; Schmidt, 2016; Sørnes et al., 2005; Whiteley et al., 2013). Cao et al. (2009) used adaptive structuration to investigate social groups that adapt to new cultural knowledge. On the other hand, Whiteley et al. (2013) show that adaptive structuration is a cultural change caused by either a unique social insight or the latest news. Both ideas and the story could create an adaptive culture that is structured by a learning environment, which then fosters a negotiated practice rather than merely an accepted practice.

This study uses the framework of adaptive structuration that focuses on two perspectives. The first perspective is structuration, and the second one is an adaptation of it (Cao et al., 2009; DeSanctis and Poole, 1994; Poole and Desanctis, 1990; Scott Poole and DeSanctis, 1992). Structuration occurs when groups or individuals implement a new system, method and procedure to achieve their needs (Furumo and Melcher, 2006; Schmidt, 2016). Meanwhile, adaptation is a behavioral aspect in which the communities or social groups act based on their cognitive appropriation. This study examines structure-in-use, in which the GoI capitalizes on its cultural knowledge to improve the SMEs. In other words, it investigates the appropriateness between all the various cultural experiences and the SMEs' cognitive structures. This study also analyzes the structural-potential aspect that can predict the cultural knowledge needed to drive the Indonesian SMEs to achieve their aims. We argue that the structural-potential perspective has social insights with forward-looking orientations that are published in the news to lever the SMEs' prospects.

\section{Structuralist theory}

Structuralists gave the impression of being those socio-cultural elements in a society or company that relates to the structure in a system that runs in general. This study notes that social components interrelate among them in either a hierarchical or flat structured system (Balzer and Moulines, 2011; Cuéllar, 2018; Koslow, 2005). This study takes into account the
Analysis of social cognition

769 
JEEE 13,5

structuralist theory to investigate the materialized structures of social cognitive reality, which exist and can vary the content of the news objectively, strictly and distantly (Cuéllar, 2018; Mikhaeil and Baskerville, 2019). It also analyzes the SMEs' empowerment that is held by the GoI, in which this study uses cultural knowledge to review the close relationship between these SMEs and this state (Shortt et al., 2012). It uses two symbolic structuralist perspectives, which are "the signified" and "the signifier" (Balzer and Moulines, 2011; Koslow, 2005). The authors, therefore, focus on the socio-cultural elements related to the structure of news about the SMEs. This structure is then used to describe various information patterns in the content of the story. We explore to understand the phenomenon of SMEs' empowerment from the content of the newspapers. It means that the authors reveal the contents of that news to identify the SMEs' enhancements, which occurred because of the GoI.

\section{Social learning theory}

The social learning theory explains that the learning process and social behavior are individual or organizational actions that obtain cultural knowledge through social interactions (Bandura and Walters, 1977; Tu, 2000). This theory stated that the learning process could be swiftly enhanced if the regulator could strengthen the SMEs' learning process with its motor reproduction and direct enforcement. This theory states that the learning process is a series of cognitive processes that involve social contexts and occur through reciprocal interactions (Pinho et al., 2019; Tu, 2000). Besides, this theory integrates behavioral and cognitive approaches from the learning process to comprehend the learning experience (Bandura and Walters, 1977; Proctor and Niemeyer, 2020). The social learning theory, in other words, explains the theory of cultural intelligence. Humans and organizations have specific behaviors and the skills to exchange information through culture or information and communication technology (ICT) (Herrmann et al., 2007; van Schaik and Burkart, 2011).

This study suggests that the complexity of behavior and learning in reciprocal interactions are critical success factors (Proctor and Niemeyer, 2020; Tu, 2000). It uses the social learning theory to explain the learning process of Indonesian SMEs through printed newspapers. In other words, this study investigates the occurred problems in SMEs that express themselves through printed newspapers. This study's investigation is also used to explain the link between situated cognition and the social intelligence theory. We, therefore, identify the degree of social dichotomization of historically cognitive experiences held by the Indonesian SMEs. We then provide a diagnosis of how to increase and enlarge the SMEs using the potential social skills available in the future. In other words, the GoI supports the SMEs' learning process when it empowers them with its authorization as if it does a reinforcement. This study, then, identifies these empowerments by their dichotomizing aspects.

\section{Situated cognition theory}

The situated cognition theory suggests that knowledge cannot be separated from the context or situation that a person or organization acquires it. Brown et al. (1989) explained that a person's or community's knowledge is embedded in the activities, contexts and culture where they learn and apply it. This theory is widely used in the learning process, which is often called situated learning. This research posits Clancey (1997), arguing that everyone's thoughts and actions always adapt to their environment, which is referred to as their situation. This study demonstrates that to predict and influence various events, people must use empirical concepts and rules. Either individual or organizational knowledge is 
built by functional contexts that are general, abstract, unlimited and apply to all the circumstances, irrespective of time or place. The cultural understanding of the community then becomes the basis for developing SMEs that are more oriented toward the future, especially in their economic, political, social, socio-cultural and sustainability aspects. Researchers claim that the GoI currently presents functional contextualism for developing SMEs. This study proposes that the GoI offers situated cognition, which is used to predict and influence future events that will probably occur. It furthermore argues that the GoI could affect the SMEs' situated learning, which could be conducive or not. We analyzed the conductively situated learning, which has been used by the GoI in the past.

\section{Social intelligence theory}

This study posits Thorndike (1920), who divides intelligence into three categories, namely, the ability to understand and organize ideas (conceptual knowledge), concrete objects (mechanical knowledge) and human cognitive culture (social experience). The social intelligence theory discusses people's or organization's abilities to understand ongoing social cognitions (Kihlstrom and Cantor, 1989, 2000). Vernon (1933) defines social intelligence more broadly, in which a person or organization can mingle with other humans, the social techniques used by them, the absorption of community knowledge and the identification of threats from external parties to them. In other words, social intelligence relates to the individual or organizational awareness of social change. This study uses human cognitive knowledge to identify the SMEs' behavior in absorbing social cognition for their businesses' development. It means that social intelligence plays an active role in solving complex problems (Nishida, 2001; Seal et al., 2006) that are experienced by SMEs. This study intends to investigate whether either the individual or organization always understands the opportunities and threats that come from the surrounding environment (Sterelny, 2007). This study, therefore, argues that most Indonesian SMEs have the social intelligence to develop and strengthen their businesses. In other words, this study takes into account how the GoI conducts social changes for enhancing SMEs through news sources. We highlighted that this published news contained the past social knowledge for constructing the SMEs' businesses, which had been held by the GoI.

\section{Engaged theory}

This study proposes that the social cognition of all the Indonesian SMEs is aligned with the learning process of scholars toward ICT. Kahn (1990) and Kearsley and Shneiderman (1998) explain that scholars are obliged to involve themselves in the learning process through their interactions with other people and by undertaking useful tasks. Kearsley and Shneiderman (1998) furthermore believed that ICT could facilitate the scholars' involvement in the learning process, and they have to achieve this process. On the other hand, O'Brien and Toms (2008) added that the conceptual framework combined with the engagement theory becomes essential when school students engage with ICT applications that offer challenges and motivation. Ford et al. (2015b) explained that this theory is used as a construct of the individual or organizational motivation and the preferences to choose relationships with others, including one's presence (physical, cognitive and emotional), and active participation. Most Indonesian SMEs learn, but it is not enough to use a traditional method; they need to add ICT to facilitate their learning. It means that Indonesian SMEs increase their learning quality. However, the Gol's policies should accompany this by improving the available ICT. This study, therefore, constructs an argument in which the GoI could alter their learning level to either "being," "doing" or "acting." We nevertheless argue that when the GoI only operates its social cognition in "being"; it cannot regulate the SMEs. Otherwise,
Analysis of social cognition 
if the GoI does "acting," it could control and manage the SMEs' enhancements. From other perspectives, this research examines the GoI using social cognition, in which they attempt to enhance the SMEs by suppressing social cognition. It also identifies the Gol's efforts to equip the SMEs with a forward-looking agenda, which they need to make them ready for any future changes.

We raise a proposition that can be used to investigate the Gol's social cognition of SMEs. To support the research proposition, the authors take the logic of Barron and Sharpe (2005) to map conflict using newspapers to understand violence in Indonesia. Barron and Sharpe (2005) used newspapers as a unit of analysis because they have a distribution network, form and illustrate the impact of the conflict. Nonetheless, the study used descriptive methods to understand conflict mapping. Finally, Barron and Sharpe (2005) found that newspapers could provide a conflict map that was accurate enough to monitor national systems that provided valuable insights related to the impact, distribution and nature of violence in Indonesia. In other words, this study accepts that newspapers can summarize social cognitive matters for their readers so they can try to understand the cultural knowledge prevailing in Indonesia. This proposition is also designed with a sequential arrangement of six theories that have been discussed before. We argue that the social cognition, presented by the GoI in newspapers, is not yet optimal. The optimal social cognition means that the cultural knowledge discussed in the newspapers could enhance, direct and lead Indonesian society. With the four main theories, this research argues that the shared collective experience of addressing the SMEs in Indonesia has some gaps among the dimensions of each theory. It means that the shared collective knowledge of the SME has spread to others (Street and Cameron, 2007), whether it is analyzed theoretically with each constructed aspect or not. In other words, the cultural knowledge of Indonesian society is not in convergence. Because of this divergence, the empowerment of the Indonesian SMEs is not happening.

From the other perspective, this study highlighted that the GoI did not focus appropriately on the intended aspect recommended by the structuration and structuralist theories. In the structuration theory, most of the cultural knowledge discussed in the newspapers did not match the structure-in-use and the structural-potential (Bryant and Jary, 2014; Giddens, 1991; Stones, 2005; Whiteley et al., 2013). We argue that the explicit understanding of the GoI about the need to improve the SMEs has some gaps. In the structuralist theory, what the new intention is for the SMEs can only be seen from the signified perspective. We argue that this theory recommends that the signifier should be the most stressed aspect (Balzer and Moulines, 2011; Koslow, 2005) of whether the GoI would improve the SMEs. The peripheral participants, which include the Indonesian regulators, are still part of the signified aspect. In the engagement theory, the social cognition of the GoI places the acting element lower. We took into account that the GoI should put acting higher than both the being and doing perspectives (Jonassen and RohrerMurphy, 1999; Kahn, 1990; Kearsley and Shneiderman, 1998; O’Brien and Toms, 2008). All of these arguments develop this study's proposition, as seen below.

\section{Proposition}

The GoI empowers SMEs with low-level support because of either a mismatched implementation of the perspectives or the misintended aspects of its structural social cognition. 


\section{Research method}

This research method uses a summative content analysis of all the articles published in the newspapers (Hsieh and Shannon, 2005; Lacy et al., 2015; Trullols et al., 2004). The use of printed newspapers means that this study uses secondary data (Creswell and Creswell, 2017; Sekaran and Bougie, 2016). The study took six national newspapers: Business Indonesia, The Jakarta Post, Kompas, Kontan, Tempo and Warta Ekonomi. It observed them from October 2016 to February 2020. We used a variety of keywords related to SMEs, such as SMEs, Ministry of Cooperation and SMEs, competitiveness, enlargement, improvement, readiness, change, exports and others. The authors argue that all these newspapers published news about SMEs that were relevant to Indonesian readers. We collected articles that were oriented toward collective knowledge (Kimmerle et al., 2010; Razmerita et al., 2014) of SMEs in Indonesia. It means that this research took into account the interactive experience of the GoI, and intended to mark the social cognition prevalent in society's discussions about SMEs.

The researcher classified each article with an identification dichotomizer based on the dimensions of the theories in this study. In its implementation, the identification process was carried out by cross-checking each news article three times to reduce the subjectivity of any judgment bias (Creswell and Creswell, 2017; Sekaran and Bougie, 2016). At the end of the data collection session, the study held a group discussion to decide on a value for the upper limit specificity of each identification dichotomizer. The group discussion is for the process of member checking (Creswell and Creswell, 2017; Sekaran and Bougie, 2016), even if the emphasis is on the content of the news. This study argues that cross-checking among researchers and content-checking in a group discussion could achieve the convergent and discriminant validities.

We used descriptive statistics to describe the preliminary data's distribution so that the data can illustrate specific patterns of information (Creswell and Creswell, 2017; Hair et al., 2006; Sekaran and Bougie, 2016). The descriptive statistics further illustrate various graphical forms to facilitate the exploration of the data. We conclude that inferences are based on the graphs we formed. We moreover deduct this graphical output that eliminates the subjectivity bias when interpreting the qualitative data (Callao and Ruisánchez, 2018; Trullols et al., 2004). This research uses an analytical tool from the WEKA Version 3-8-3. This tool is used to explore the data's patterns (Witten et al., 2011). It uses the J48 C.45 algorithm, which can bring up a statistical analysis of the data's patterns into a decision tree (Apté and Weiss, 1997; Kebede et al., 2017; Panigrahi and Borah, 2018; Patil and Sherekar, 2013; Raj and Nandhini, 2018). In other words, this study uses the ten-fold cross-validation test mode with an expression of structuration for the leaf nodes. It means that the researchers formulate the data patterns when compiling the decision tree's structure.

All the processes used during the research method are summarized in Table 1 and Figure 1. Table 1 presents the formulation of the data's identification dichotomizer, while Figure 1 shows the process of the data's formulation when compiling the structure of the decision tree.

\section{Analytical results}

This research collected 1,354 news articles; it eliminated 52 news articles because they were not relevant to this study's context. In the end, the data collection phase succeeded in identifying 1,302 published news articles, which could be processed into the probabilistic analysis. Table 2 presents a description of the data from the news articles related to SMEs in Indonesia.
Analysis of social cognition 
JEEE

13,5

774

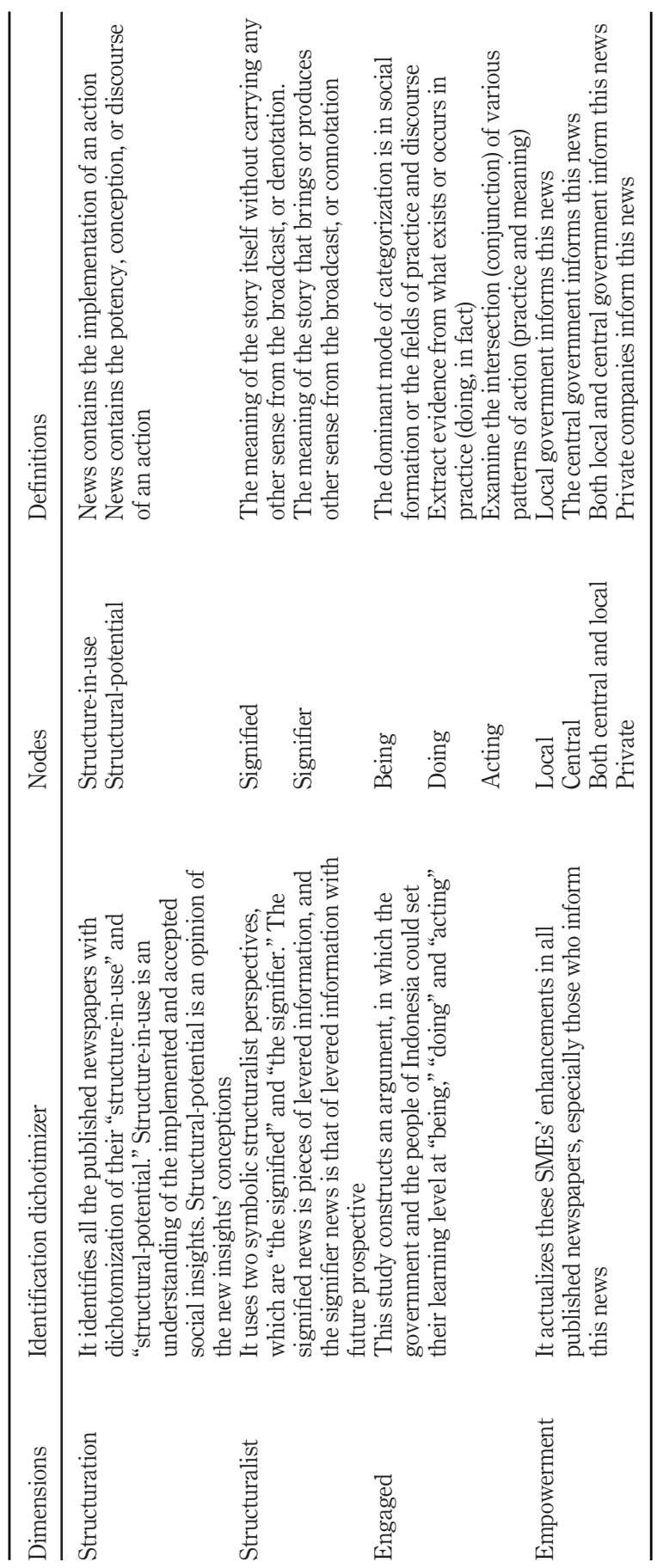

Table 1.

Formulation of a data identification dichotomizer 


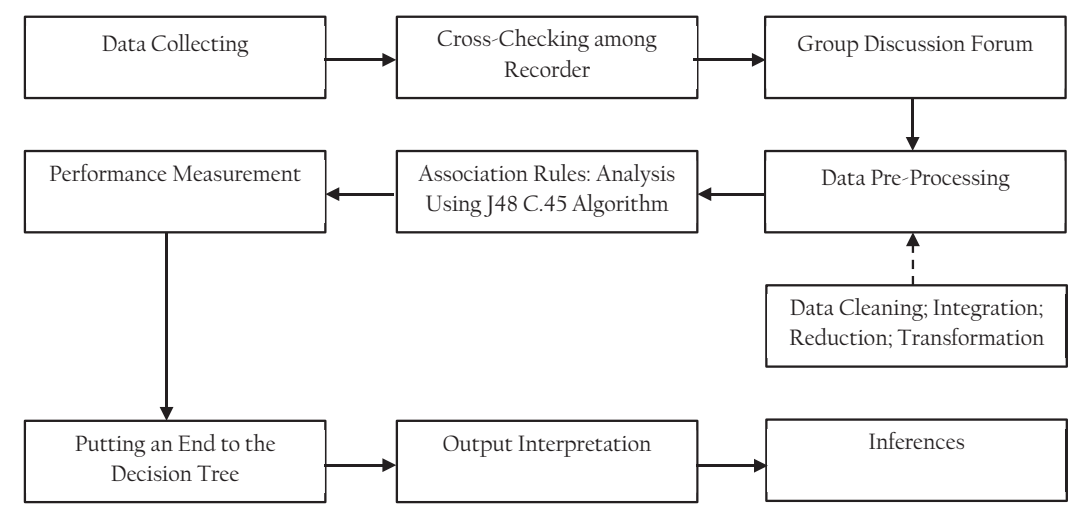

Analysis of social cognition

This table illustrates the distribution of observational data in this study. The study noted that the search for news about SMEs had problems with the availability of data from years ago because the newspapers did not keep extensive records of their back copies; hence, the data collected from 2016 only had ten $(0.77 \%)$ news articles. It appears that Bisnis Indonesia and Warta Ekonomi have the most substantial proportions, namely, 25.42 and $30.72 \%$, respectively. The six newspaper publishers did supply sufficient previous articles to satisfy the required number for an accurate analysis, which could then determine the probability of empowering the SMEs with the cultural knowledge of the GoI. From a structural and structuralist perspective, news articles containing structure-in-use (57.68\%) and the signified $(64.29 \%)$ dominate the universe of social cognitive speech for SMEs. This study suggests that the implementation of the "acting" in the news empowers SMEs. This

\begin{tabular}{|c|c|c|c|c|}
\hline Descriptions & Characteristic & Total & $(\%)$ & \\
\hline \multirow[t]{6}{*}{ Newspapers } & Bisnis Indonesia & 331 & 25.42 & \\
\hline & Jakarta Post & 72 & 5.53 & \\
\hline & Kompas & 200 & 15.36 & \\
\hline & Kontan & 274 & 21.04 & \\
\hline & Tempo & 25 & 1.92 & \\
\hline & Warta Ekonomi & 400 & 30.72 & \\
\hline \multirow{2}{*}{ Structuration theory } & Structure-in-use & 751 & 57.68 & \\
\hline & Structural-potential & 551 & 42.32 & \\
\hline \multirow[t]{2}{*}{ Structuralist theory } & Signified & 837 & 64.29 & \\
\hline & Signifier & 465 & 35.71 & \\
\hline \multirow{3}{*}{ Engagement theory } & Being & 712 & 54.69 & \\
\hline & Doing & 288 & 22.12 & \\
\hline & Acting & 302 & 23.20 & \\
\hline \multirow[t]{4}{*}{ Empowerment } & Central government & 464 & 35.64 & \\
\hline & Local government & 214 & 16.44 & \\
\hline & Both central and central government & 393 & 30.18 & \\
\hline & Private & 231 & 17.74 & \\
\hline \multirow[t]{5}{*}{ Year of publication } & 2016 (October-December) & 10 & 0.77 & \\
\hline & 2017 & 403 & 30.95 & \\
\hline & 2018 & 392 & 30.11 & Table 2. \\
\hline & 2019 & 404 & 31.03 & Description of the \\
\hline & 2020 (January-February) & 93 & 7.14 & data \\
\hline
\end{tabular}


JEEE 13,5

\section{6}

implementation shows the real developments in the SMEs' businesses. From the perspective of the engagement theory and empowerment, this study suggests that news articles dominate the actual actions taken by the GoI in the stage of "being" (54.69\%) and the Central Government (35.64\%). We took into account that the social cognition of the SMEs' empowerment in Indonesia tends toward the "structure-in-use," the "signified" and the "being." When the social cognition for Indonesian SMEs was in these tendencies, the enhancement of the SMEs would experience difficulties, because of mismatched and unoptimized social experiences. The matched social skills have to exist in the balance between structure-in-use and structural-potential, and the optimized ones should be part of the "signifier" and the "acting." Whether the GoI could reach this matched and optimized human knowledge or not, this study believes that Indonesia is now at the best point to improve the SMEs' businesses.

This study analyzes the structure of the social cognition that has been running for 3.5 years. It started with the structuration theory. Figure 2 illustrates observational data from the first month (October 2016) to the 41st month (February 2020). We used the structuration theory to map the structure of the social cognition that affected the conception, implementation and acceptance of society toward the reporting about SMEs in Indonesia (Bryant and Jary, 2014; Giddens, 1991; Stones, 2005). On the other hand, this study recognizes the ICT factors that contribute to the formation of social cognition structures for the social groups that are influenced by online news media (Cao et al., 2009; Furumo and Melcher, 2006; Schmidt, 2016; Sørnes et al., 2005; Whiteley et al., 2013). This research suggests that structure-in-use dominated 34 months of the observation period. This dominance meant that various programs, which appeared to empower the SMEs, already existed. It means that the GoI played a passive role and only followed the established practices (Bryant and Jary, 2014; Sinclaire and Vogus, 2011; Stones, 2005; Whiteley et al., 2013) that were already in place. The Indonesian regulator, at that time, experienced a cognitive disruption in which it alone acted to implement aspects of the policies it had designed.

For the second perspective, this study analyzes the incidence of published articles discussing the empowerment of SMEs in Indonesia. Figure 3 illustrates 41 months of observational data from structuralist aspects. The structuralist theory provides a summary of the meaning of written news content and explains the coverage of the SMEs in dimensions that are somewhere between the signified and the signifier (Balzer and Moulines, 2011;

Figure 2.

Published articles on the structuration perspective

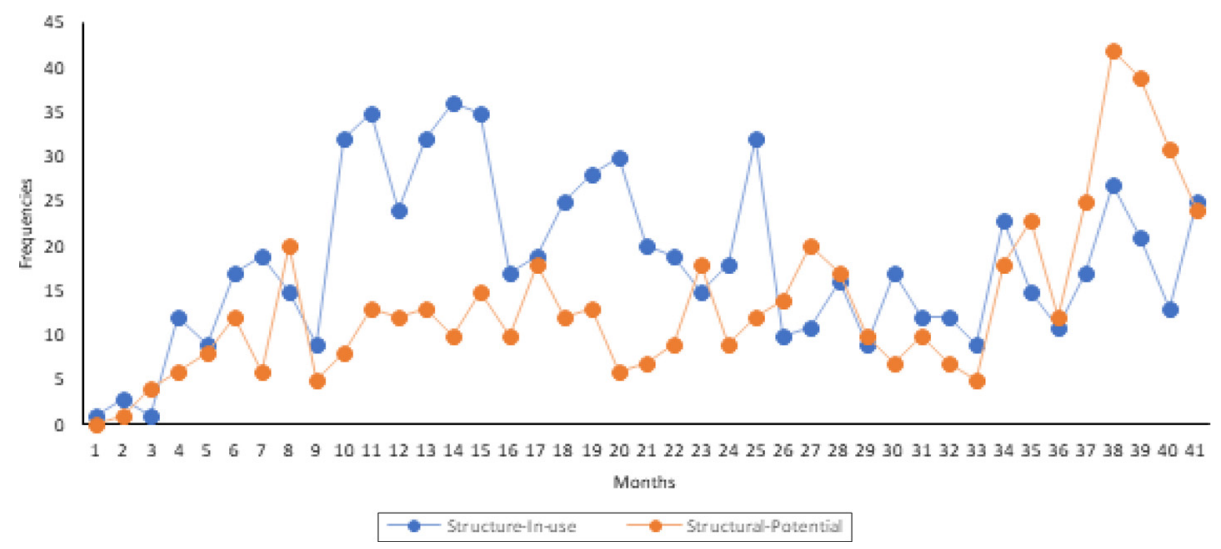




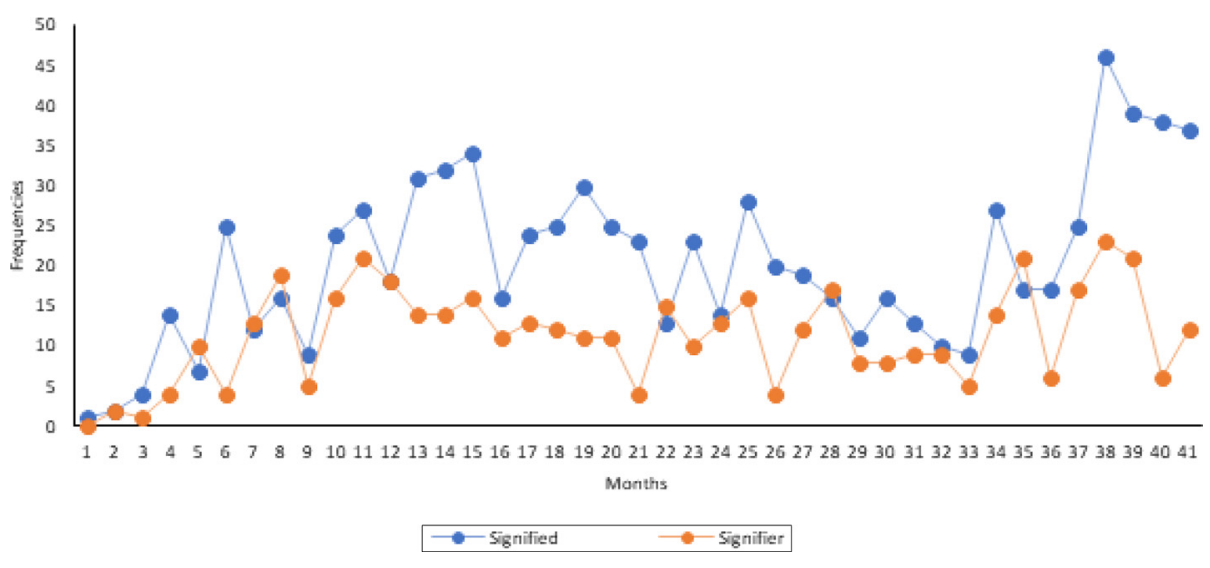

Analysis of social cognition

Koslow, 2005; Mikhaeil and Baskerville, 2019). We interpreted that the news phenomenon is relevant to the empowerment and improvement of the SMEs' business in Indonesia through a symbolic structuralist perspective (Balzer and Moulines, 2011; Mikhaeil and Baskerville, 2019; Shortt et al., 2012). We noted that signified consistency was more dominant over the 41 months of the observation period. This study inferred that many written articles only emphasize the factual conditions that exist in the development of SMEs in Indonesia. In other words, all the published articles gave a core signal that the SMEs' empowerment is only seen over the short term because of the implementation of backward-looking policies (Balzer and Moulines, 2011; Dobson and Khatri, 2000; Koslow, 2005). We also documented that the SMEs' publish data in which the signified perspective increased rapidly in the 36th month of the observation period.

For the third perspective, this research used the engagement theory to analyze the problem. Figure 4 explains the observed data for the being, doing and acting dimensions of the engagement theory. This study found that the dynamic structure of the news coverage of the SMEs, as permitted by the Gol's publishing laws, helped to establish relationships with the newsreaders and society in general (Ford et al., 2015b; Kahn, 1990; Kearsley and

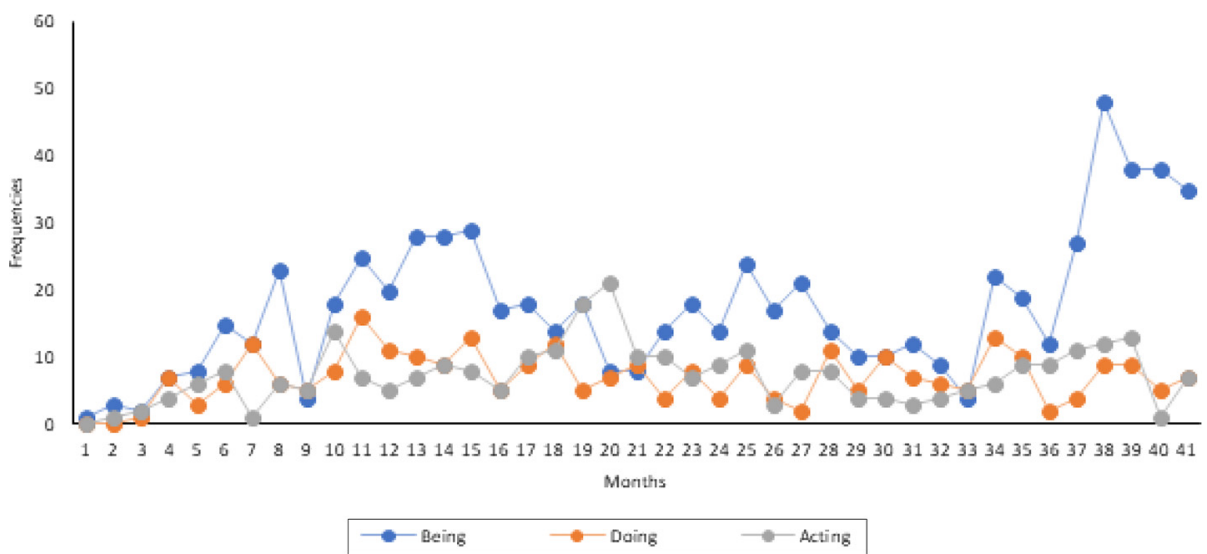

Figure 4. Published articles on engaged perspectives 
JEEE
13,5

778

Shneiderman, 1998; Loveridge, 2013). We identified that the directional movement was between doing and acting, but the deviant one was being. This gap got larger during the 36th month of our observation period. We furthermore believed that news reports about the SMEs' empowerment were only to be found in a previous discourse. Published articles on the SMEs' enhancements were only emphasized for their factual news about the SMEs' empowerment (Mikhaeil and Baskerville, 2019; Shortt et al., 2012). These articles did not contain a future empowerment agenda (Cuéllar, 2018; Wendt and Seymour, 2010) for those SMEs that have the potential to increase their explicit knowledge. The empowerment agenda usually acts as a stimulant (Gey, 1988; Koslow, 2005; Owenby, 2002) to force the Indonesian SMEs to become more organizationally ready to face coming changes.

During the first stage of this study, a graphical diagnosis of the perspectives of the three stages of structuration, structuralism and engagement was placed into two diagnostical models. In this phase, this study analyzed the probability test for the knowledge structure's mechanism. Table 3 summarizes the statistical output of the WEKA analytical tests based on the J48 C-45 algorithm. The authors infer that the accuracy of the correctly classified instances (data) have levels of 81.11 and $80.65 \%$ in Models 1 and 2, respectively. We furthermore took into account the kappa statistics, which recommended the correctly sensitive meaning between the data's classification and its class of 0.6036 for Model 1 and 0.5927 for Model 2 (Panigrahi and Borah, 2018). We inferred from the kappa statistical results that by producing the data's classification, it would be more than 0.50 , which formulates the correctly classified data. This study interpreted both the root mean squared errors (RMSE) and root relative squared errors (RRSE), which provided an error probability in the decision tree model of $38.16 \%$ with a model accuracy of $77.24 \%$ for Model 1 . These measurements were 38.73 and $78.39 \%$ for Model 2. Both of these measurements can be interpreted as a decision tree model with adequate validity (Carpentier and Cammaerts, 2006). The researchers then concluded that the model has the goodness of accuracy, and it is categorized as being sufficiently powerful to predict (Kebede et al., 2017; Panigrahi and Borah, 2018) the social experiences of the news reports about the SMEs.

We combined Models 1 and 2 into Model 3, which has a more extended algorithm for the investigation of the cultural knowledge contained in the newspapers, in comparison with the two earlier models. Model 3 induced the empowerment agents, which are the central governments, local governments and private companies. We consistently show the results of the statistical probability analysis. The combined Models 1 and 2 (Model 3) indicated an improvement, which is a better goodness probability and shows the human knowledge of the Indonesian SMEs.

This study continues by considering the following results of the probability analysis with the accuracy of each classification. Table 4 illustrates the detailed accuracy of the

Table 3.

Results of probability analysis

\begin{tabular}{lcrr}
\hline & \multicolumn{3}{c}{ Probability results } \\
Indicators & Model 1 & Model 2 & Model 3 \\
\hline Correctly classified instances & $81.11 \%$ & $80.65 \%$ & $81.18 \%$ \\
Incorrectly classified instances & $18.89 \%$ & $19.35 \%$ & $18.82 \%$ \\
Kappa statistic & 0.6036 & 0.5927 & 0.6055 \\
Mean absolute error (Carpentier and Cammaerts) & 0.2890 & 0.2984 & 0.2894 \\
RMSE) & $38.16 \%$ & $38.73 \%$ & 0.3824 \\
Relative absolute error (Zhu and Kraemer) & $59.19 \%$ & $61.11 \%$ & $59.28 \%$ \\
RRSE & $77.24 \%$ & $78.39 \%$ & $77.39 \%$ \\
Total number of instances & 1,302 & 1,302 & 1,302 \\
\hline
\end{tabular}




\begin{tabular}{llccccccccc}
\hline & & & & & & & & & PRC \\
Models & Class & TP rate & FP rate & Precision & Recall & F-measure & MCC & ROC area & area \\
\hline Model 1 & Structural-potential & 0.688 & 0.099 & 0.837 & 0.688 & 0.755 & 0.611 & 0.829 & 0.792 \\
& Structure-in-use & 0.901 & 0.312 & 0.797 & 0.901 & 0.846 & 0.611 & 0.829 & 0.828 \\
& Weighted average & 0.811 & 0.222 & 0.814 & 0.811 & 0.808 & 0.611 & 0.829 & 0.813 \\
Model 2 & Structural-potential & 0.672 & 0.095 & 0.839 & 0.672 & 0.746 & 0.602 & 0.827 & 0.760 \\
& Structure-in-use & 0.905 & 0.328 & 0.790 & 0.905 & 0.844 & 0.602 & 0.827 & 0.831 \\
& Weighted average & 0.806 & 0.229 & 0.811 & 0.806 & 0.802 & 0.602 & 0.827 & 0.801 \\
Model 3 & Structural-potential & 0.691 & 0.100 & 0.836 & 0.691 & 0.757 & 0.613 & 0.765 & 0.809 \\
& Structure-in-use & 0.900 & 0.309 & 0.799 & 0.900 & 0.847 & 0.613 & 0.832 & 0.835 \\
& Weighted average & 0.812 & 0.220 & 0.814 & 0.812 & 0.809 & 0.613 & 0.832 & 0.805
\end{tabular}

Analysis of social cognition

Notes: TP: True positive; FP: False positive; MCC: Merkel cell carcinoma; ROC: receiver operating characteristics; PRC: Precision-recall curve

Detailed accuracies

Table 4. of data class

classification's output of the J48 algorithm. It shows that the data has been classified into different classes, with $81.2 \%$ being correct for the true positive rate (TP rate) in Model 3. The results for Models 1 and 2 are 81.10 and $80.60 \%$, which are similar. Furthermore, the probability of the data's relevancy has a precise value of 0.814 in Model- 3 (Raj and Nandhini, 2018). The data's consistencies are also supported by the receiver operating characteristics (ROC) area, which interprets the relationship between false and TP areas with values of $0.829,0.827$ and 0.832 consecutively for these models (Patil and Sherekar, 2013). Based on Tables 3 and 4, the researchers consider that all the models show sufficient conditions for further analysis through the decision tree. We argue that the assessment of classified data must accurately fulfill all the normative criteria, although they often become a fuzzy problem (Patil and Sherekar, 2013). This study, therefore, infers the cultural knowledge about these SMEs, as published in the news, is correct for what they intend to empower.

First of all, this study presents three models to explain the social cognition of the news about Indonesian SMEs. Figure 5 illustrates the decision trees output of observed data, which is Model 1. We designed a chronologically analytical event that is structuration, engaged, sets of media and structuralist theories. On the other hand, we also created Model 2 , as presented in Figure 6. Model 2 has a chronologically analytical event, which can be structuration, engaged, empowerment and structuralist sequentially. This study uses

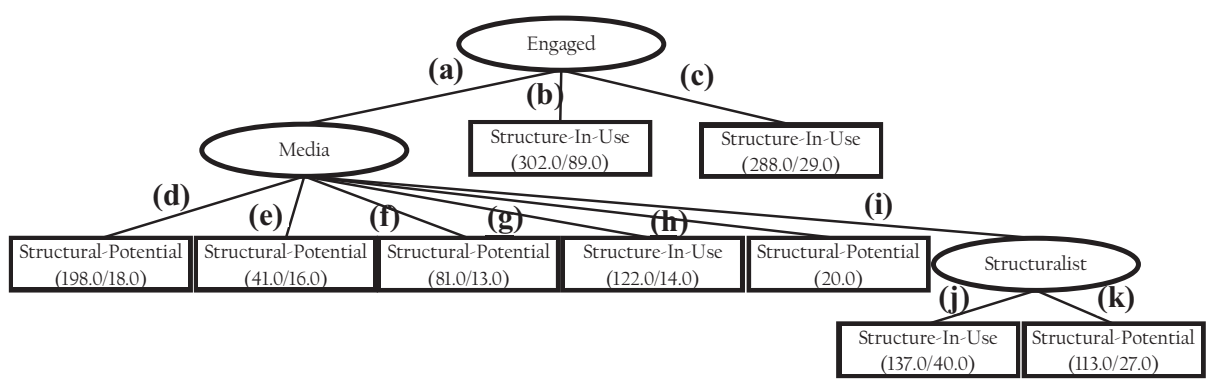

Notes: (a) Being; (b) Acting; (c) Doing; (d) Bisnis Indonesia; (e) Jakarta Post; (f) Kompas; (g) Kontan; (h) Tempo; (i) Warta Ekonomi; (j) Signified; (k) Signifier

Figure 5. Decision tree of Model 1 


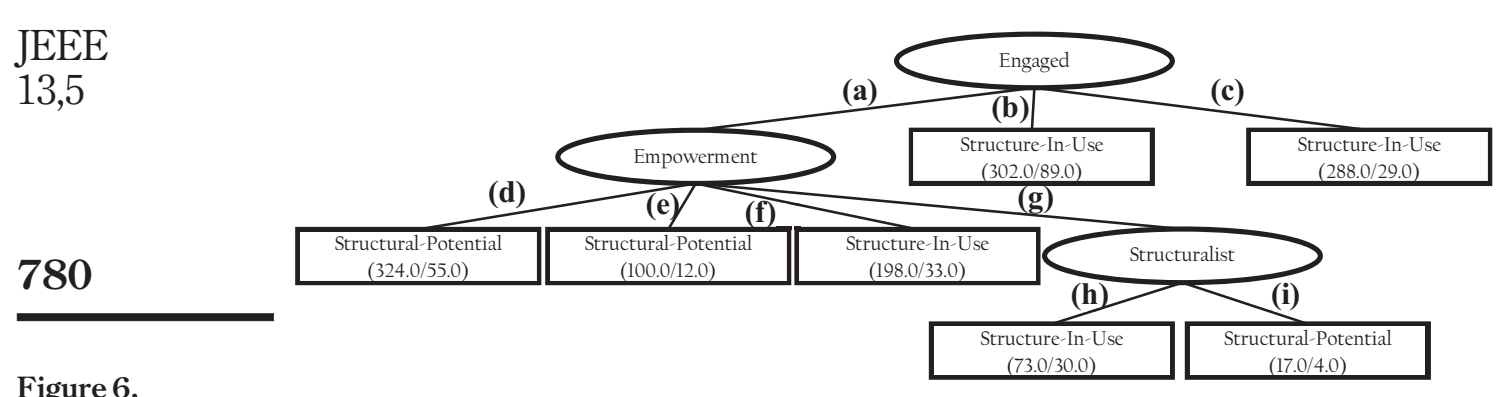

Decision tree of Model 2
Notes: (a) Being; (b) Acting; (c) Doing; (d) Central; (e) Private; (f) Government (both); (g) Local; (h) Signified; (i) Signifier

structuration as a data class to form decision trees for both models. The process of developing the patterns in Models 1 and 2 is the same. The dynamics structure involved in the news about the SMEs' is more likely to be in the classification of being. This study suggests that the interpretation in "being" has the highest amount of data and is crucial for the pattern's formation. We conclude that the published media could capture these discourses, and the various meanings in them, in Model 1. In the second phase of the analysis of the probability data, the most substantial proportion of the published media considers that the focus of the news is oriented toward the "structural potential." In the final stage of the analysis of the probability data, Warta Ekonomi continuously presents a point of view of the structuralist perspective from the "signified" probability's position and ends with the "structure-in-use" leaf node.

From the total data of 1,302 articles, we explain the analytical process for the amount of data in the "being" of 712. This data amount, then, is divided between the six newspapers. Based on this number, the most significant number of articles appeared in Warta Ekonomi, and these number 250 articles producing data, which are analyzed for their probability emergence patterns. The data is then associated with the structuralist dimension, which divides the 250 items of data into two classifications, which are 137 "signified" pieces and 113 "significant" items. The 137 signified fragments of data and the statistical analysis raises the possibility that 40 of the items of data are misclassified. In other words, 97 issues of data are classified as being signified accurately. This classification means that for the 113 pieces of "signifier" data, possibly 27 of them are incorrect. In other words, 86 items of data are accurately classified as being "signifiers." All the data tend to form a decision tree for the "signified" perspective, with leaf nodes for "structure-in-use," in which it is evidenced that the "signified" data, numbering 97 items, is higher than the "signifier" one of only 86 pieces.

Model 2's classification of "being," as per the engagement theory or the discourse about the Indonesian SMEs' empowerment, tends to be captured by the newspapers. In this case, the GoI and the private sector will bring up these discourses as a form of "structuralpotential." However, the GoI focuses more on the reporting of implemented activities, which are in terms of the "structure-in-use." This research took note that the local governments behaved differently in all the news articles, which is part of the "signified" form. It means that the local governments' actions were emphasized in the leaf node of "structure-in-use."

This study continued to combine Models 1 and 2, which is intended to examine the robustness of the results of the cultural knowledge from the SMEs' news. Figure 7 combines the elements of the SMEs' empowerment knowledge in Model 3 as a whole. Model 3 draws on the structure of the "engaged" dynamics of the SMEs' news, which shows the frequency 


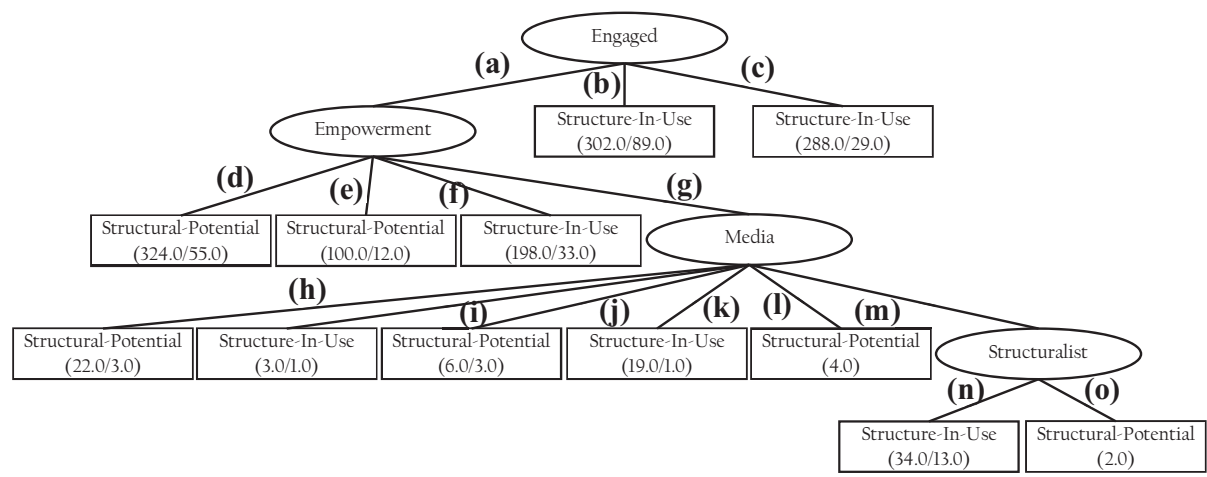

Analysis of social cognition

781

Notes: (a) Being; (b) Acting; (c) Doing; (d) Central; (e) Private; (f) Government (both); (g) Local; (h) Bisnis Indonesia; (i) Jakarta Post; (j) Kompas; (k) Kontan; (1) Tempo; (m) Warta Ekonomi; (n) Signified; (o) Signifier

Figure 7.

Decision tree of Model 3

of the appearance of "being." These discourses occur through the Gol's agents and private agents. Meanwhile, the GoI emphasized the structure of the news through the "structure-in use" for all the SMEs' empowerment activities. This study suggests that there are differences in the appearance of the actualization activities carried out by the local governments. We highlighted that media factors play a role in explaining the structures that influence people's social insights concerning the conceptions of "structural-potential" and "structure-in use" (Aksoy et al., 2013; Bandura, 2003; Stones, 2005). This research noted that Warta Ekonomi provided a new perspective on the meaning of "structuralist-signified" and emphasized "structure-in use" for future SMEs' enhancements.

In Model 3, we finally found that the sequential probability association among structuration, structuralism, newspapers and engagement perspectives produces robust results from the statistical probability test. This analytical result also recommends a new intuitive meaning. The researcher formulated that the SMEs' social learning in Indonesia is still limited to the implemented policies, which this study interpreted as being backwardlooking orientations and not yet related to the discourse about the future. It means that the published articles for the SMEs' empowerment are still trapped in the pseudo-collective performance produced by the community or the social environment (Brown et al., 1989; Bryant and Jary, 2014; Hundleby, 2010; Loveridge, 2013). The many implementations of a potential new discourse have not yet given the SMEs' an understanding that they have grown and are successful in contributing to the country's gross domestic product (Giddens, 1991; Magnus and Callender, 2004; van Schaik and Burkart, 2011).

\section{Research findings}

These research findings focused on the three decision trees that we analytically found. Overall, both models explain the level of knowledge possessed by the GoI. This knowledge is still at the real level of discourse on the empowerment of the SMEs' businesses. This study then inferred ecological psychologies through the published media and social cognition's dimension of empowerment. We find that "signified" in the structuralist aspect is at the end of the decision tree. This decision is based on the number of classified instances, which can be listed as "signified," which is more significant in comparison to the "signifier" (Balzer and Moulines, 2011; Koslow, 2005). Both models show that "structure-in-use" is the final leaf 
JEEE 13,5

782 node in the flow of social thought in a structured pattern. It means that the inference of Models 1 and 2 is similar to the interpreted results of the first-stage graph diagnosis of the three main theories used by this study. The authors argue that the empowerment of the Indonesian SMEs is still at a low level if judged by the series of "being - structure-in-use signified." The GoI should empower the SMEs through a series of actions that are from the series "acting - structural-potential - signifier." This study concludes that the low level of empowerment makes the Indonesian SMEs lethargic and reluctant to grow. This research takes into account some of the lines of thought from the relevant articles by Boudreaux et al. (2019), Panjaitan et al. (2020), Pinho et al. (2019), Wang et al. (2019) and (Tu, 2000) accompanied by all their research findings. The authors stepped in to choose these articles because of the lack of relevant research in Indonesia related to SMEs.

This research argues for the formulation of the realized social cognition, which discusses the SMEs' empowerment using the following arguments. First, this study notes that the most significant probability of "structure-in-use" implies that the contents of the news have not optimally empowered the SMEs. In other words, the optimization's purpose should have referred to the element of social cognition that could drive the SMEs' to improve, direct and lead themselves. From a governance perspective, a series of regulations, programs and SME empowerment activities have not mobilized their capabilities and resources to reach a fully empowered position (Shortt et al., 2012). For example, this study recommends a policy that the Indonesian Ministry of Cooperation and SME has to hold the mobilization of SMEs' capabilities and resources itself. Another policy recommendation is that this ministry should also cluster these SME in their industrial specializations and map the value chains among them. All the published articles are only fulfilled by the role of the GoI and the private sector, which does not have a proper mission and vision to increase the level of the SMEs' businesses progressively.

On the other hand, the empowerment of the SMEs tends to merely be because of the prospect of their exposure to organizational progression in comparison to any strict regulatory assistance (Del Brìo and Junquera, 2003; Hessels and Kemna, 2008). This study analyzed and identified through the "structural-potential" that is defined in this probability analysis. Social cognition that has been published in all the mass media in Indonesia has not yet reached this "structural-potential." It means that these actors or organizations implemented the SMEs' empowerment without being accompanied by the "signifier" policies. The GoI should facilitate strategies to provide growth opportunities and potential therapies for the SMEs to accelerate the process of enhancing their businesses. It means that the Gol's policies are intended not only to meet the current needs of the SMEs but also for potential future improvements (Kureshi et al., 2010; Parker et al., 2009). The "structuralpotential" systems are also expected to increase the interest of creditors or investors in developing the SMEs' businesses in Indonesia. The authors, therefore, argue that the GoI needs to measure each SME scalability nationally, and then equip it with experiential knowledge, which is relevant for its future sustainability. In other words, the GoI should not focus on financial and administrative expertise, or on what Panjaitan et al. (2020) suggested.

Second, this study elaborated on the "signifier" itself. The authors noted that most of the articles published in Indonesian newspapers only presented the "signified," without being influenced by future stimuli. This study proposes that future incentives should include making a guide and knowledge management system, in which the Indonesian SMEs could get what they need in the future (Anantadjaya et al., 2011; Saini, 2013). With the orientation of prospects, most Indonesian SMEs could anticipate dynamic and uncertain environments. In other words, the "signifier" is the GoI, who has to facilitate the SMEs to get their organizational readiness to a level where they can face their 
competitors (Balzer and Moulines, 2011; Irjayanti and Azis, 2012; Koslow, 2005; Singh et al., 2010). In other words, the "signifier" is governmental programs that could help the SMEs to increase their organizational readiness for change (Balzer and Moulines, 2011; Hidayanto et al., 2013; Koslow, 2005). We identified the potential policies for the Indonesian SMEs and whether the social networks facilitate them or not. These facilitations could probably improve their businesses, so they can find more extensive supply chains and improve their customer relations (Irjayanti and Azis, 2012; Singh et al., 2010). It proposed that the Gol's action should lead ahead of these SMEs. It also meant that the GoI participated not only in publishing its past work, but also its prospective agenda for stimulating all the SMEs. This research recommends that the GoI conduct a policy of value chain mapping for each SME. This policy should ensure the mapping explains the connectivity of each SMEs with firms listed on the Indonesian Stock Exchange.

Third, this study acknowledges that the GoI was in the "being" perspective. It proposes that what the GoI did is far from what it should be doing in the "acting" perspective. It means that this study raises a problem for the SMEs' empowerment in Indonesia, as the GoI itself did not produce the required social cognition and social learning (Bandura and Walters, 1977; Herrmann et al., 2007; Tu, 2000) for the SMEs. In other words, the GoI has to act using its social intelligence to solve all the SMEs' business problems (Kihlstrom and Cantor, 2000; Nishida, 2001; Seal et al., 2006; Sterelny, 2007). We also argue that the GoI has to dominate the situated social cognition (Brown et al., 1989; Clancey, 1997; Kirshner and Whitson, 1997), which is used to lead all the SMEs to achieve their readiness for change (Armenakis et al., 1993; Hidayanto et al., 2013; Weiner, 2009). In other words, the GoI should be a leader, through its social intelligence, and capture the situated cognition instead of it being a follower. With the acquisition of social learning and social cognition, the GoI could improve its policies by designing a national integrated communication system for the integration between itself and the SMEs. It means that the GoI has to build the SMEs national dashboard, which is useful for integrating the activity and business flows of resources, knowledge and others. In other words, the authors recommend that connectivity among SMEs has to be built to show the power of the SMEs and their contribution to the gross national products.

In the last stage, this research developed an implied strategy that is derived from the three previous findings. We propose innovation and leadership agendas for the SMEs' empowerment, by suppressing policies that are funded from either the Gol's or the local governments' budgets, creating a curriculum for social cognition and social learning and developing a knowledge repository. The first suppressed policy should be the submission of special fund allocations, which the GoI and local governments use to build their budgets for social learning and social cognition. These funds are focused notably on the development and dissemination of social learning and social cognition (Bandura and Walters, 1977; Herrmann et al., 2007; Tu, 2000) for the SMEs. In other words, this development and dissemination of social learning and social cognition have to be the nation's mission (Bandura and Walters, 1977; Herrmann et al., 2007; Tu, 2000), which is the Gol's responsibility. We acknowledge that the budget for the SMEs' empowerment in Indonesia is held with generally accepted practices that are not based on an integrated mission. In its implementation, the budgeting practice for the SMEs' empowerment often overlaps among the ministries, both for the program types and the process of achieving the set targets. This study, finally, argues that the GoI should copy what Singapore and Thailand did. Singapore created The National Board for SMEs to reduce overlapping policies and then created a friendly-business environment for all those SMEs. Thailand set up the Office of SMEs Promotion (OSMEP), which is used to promote its SMEs' products internationally. 
JEEE 13,5

The second suppressed policy is for the development of curricula for social learning and social cognition, for both the owners and executive officers of Indonesian SMEs. The authors argue that the curricula should be aligned with Indonesia's missions and goals, which are primarily to increase its gross domestic product. We propose that curricula should include learning goals and objectives. To explain the curricula for Indonesian SMEs, researchers take the logical flows of thought from Boudreaux et al. (2019), Panjaitan et al. (2020), Pinho et al. (2019), Wang et al. (2019) and (Tu, 2000). Notably, the curricula for the Indonesian SMEs arrange for them to be aware of social cognition with "acting - structuralpotential - signifier" (Boudreaux et al., 2019; Panjaitan et al., 2020; Wang et al., 2019). In other words, these SMEs need social learning and social cognition, from which they could develop their forward-looking orientation (Crespy and Vanheuverzwijn, 2019; Pinho et al., 2019; Tu, 2000), which is used to empower their organizational readiness and their readiness for change (Coleman et al., 2019; Panjaitan et al., 2020; Puklavec et al., 2018). The contents of the curricula are adaptive structuration, social intelligence, situated learning, social cognition, social networks, engagement, social cognitive and other similar things. This study recommends that the GoI should be responsible for designing these curricula for the Indonesian SMEs. The design could be through either the Ministry of Cooperation and SMEs or the Ministry for Industry.

The third emphasized policy is the need for a national knowledge repository for all the Indonesian SMEs. The GoI has to facilitate these SMEs with this knowledge repository to empower culturally cumulative experiences among them. With this knowledge repository, the GoI would possess a knowledge management system that is useful for sharing, disseminating or exchanging organizational skills (Maier and Hadrich, 2011; Pun and Nathai-Balkissoon, 2011). It means that the GoI could gain explicit knowledge from people with vast experience (Child and Shumate, 2007; Maier and Hadrich, 2011). This study could also share the social cognition and social learning of the industrial sector with other sectors. It inferred that this knowledge repository should be accompanied by a curriculum that is systematic and sustainable for the needs of the SMEs' clustered industries. The curriculum, as well as the knowledge repository, could produce learning systems to give an individual or organizational knowledge and skills (Bollinger and Smith, 2001; Gherardi, 2009). In other words, the knowledge repository could integrate and spread cognitive skills and experiences. The GoI should also incorporate all the SMEs' empowerment efforts into the knowledge management system (Child and Shumate, 2007; Gherardi, 2009; Maier and Hadrich, 2011; Pun and Nathai-Balkissoon, 2011), which may simultaneously strengthen their social cognition and social learning.

\section{Conclusion, limitation and future research}

First of all, this study investigates the problems that the Indonesian SMEs have faced for the past decade. It raises queries about the social cognition, which the GoI has disclosed in certain newspapers. It means that this study made deductions based on the theories of social learning, situated cognition and social intelligence. We found that policies for the SMEs' empowerment were suppressed. First, the sluggishness of the Indonesian SMEs is because of some fallacies in their social cognition. Second, this study elaborated on what the causal factor was of the SMEs' sluggishness. It explains that the fallacies in their social cognition were because of the identified inconsistencies in their structuration, structuralism and social learning. In witnessing this sluggishness, this research collected data from six newspapers from October 2016 to February 2020 and obtained 1,354 articles. These newspapers were Business Indonesia, The Jakarta Post, Kompas, Kontan, Tempo and Warta Ekonomi. We then analyzed the news articles using the WEKA and the J48 algorithm. 
This study found that the GoI empowered the SMEs that were "being - structure-in-use signified." This study, however, recommended "acting - structural-potential - signifier." This study concluded that the low level of empowerment made the Indonesian SMEs lethargic. It presented three particular pieces of evidence. First, social cognition, which is found in all the mass media published in Indonesia, has not yet reached its "structuralpotential." Second, most published articles in Indonesian newspapers present only the "signified" matter, without being bothered by future stimuli. Third, the GoI acted in the "being," which is far from what it should be doing in the "acting" perspective. From these pieces of evidence, this study constructed its strategies. We offer three kinds of policies below. The first is the submission of special allocation funds from which the GoI and the local governments develop their budgets for the SMEs' social learning and social cognition. The second is the development of social learning and social cognition's curricula for both the SMEs' owners and executive officers. The third is the need for a national knowledge repository for all the Indonesian SMEs. This repository is used for the dissemination of knowledge.

The authors present some possibilities for the limitations of this research. We took into account that this study assumes the SMEs are all the same, without industrial clustering. It considers that the need for social learning and social cognition by the unclustered industries is equal. The suppressed policies, which are made by this study, do not differentiate between social learning and social cognition for the SMEs in the clustered sector. This study, however, recommends that future research distinguishes any experiential knowledge, which may be needed by the different industrial sectors. It means that a dashboard of knowledge management systems and the curricula for the SMEs should be leveled, clustered and specialized. Secondly, we acknowledge that Indonesia is an emerging country, and its economic structure has three levels of contributors; the companies listed on the Indonesian Stock Exchange, then the SMEs and the lowest level is the underground economy. This study ignored the process of knowledge sharing from most of the leading companies with the SMEs. It recognized some difficulties in mapping the SMEs in foster-son relationships with the listed companies. It highlighted that the SMEs that are in foster-son relationships have an excellent transformation process for the knowledge they gain from the listed companies. It also considered the equal position of SMEs without a transformation process experience. We could argue that subsequent studies have to differentiate between the SMEs' in foster-son relationships and those that are not.

Thirdly, we did not distinguish the levels of success for the empowerment programs, which are conducted by either the GoI or the local governments. This study recognizes that we did not measure success levels. It means that we only focused on the knowledge content. Future research should probably differentiate between the printed news, which highlights a success, and that which does not. This new research would become more attractive because of the empowerment of successful news stories. We raise a new issue about the SMEs' capitalizing on cultural knowledge gained from the news stories about success or failure. This research considers all the news published about SMEs by the GoI to be holistic. It means that this study did not differentiate who produced the news articles about the SMEs. This news would probably come from the Ministry of Cooperation and SME, the Ministry for Industry, the Trade Ministry or some others. We argue that future research would be more interesting when it identifies the principal producers of news about the SMEs. This new research could finally infer who empowers the Indonesian SMEs.
Analysis of social cognition

785 
Aksoy, L., Van Riel, A., Kandampully, J., Bolton, R.N., Parasuraman, A., Hoefnagels, A., Migchels, N., Kabadayi, S., Gruber, T., Loureiro, Y.K. and Solnet, D. (2013), "Understanding generation Y and their use of social media: a review and research agenda”, Journal of Service Management, Vol. 24 No. 3, pp. 245-267.

Anantadjaya, S.P., Nawangwulan, I.M., Sibarani, M. and Riwoe, J.C. (2011), "Firm's diversification strategy, risk and incentives (viability study on Indonesian SMEs)", European Accounting Review, Vol. 20 No. 1, pp. 1-29.

Apté, C. and Weiss, S. (1997), "Data mining with decision trees and decision rules", Future Generation Computer Systems, Vol. 13 No. 2-3, pp. 197-210.

Armenakis, A.A., Harris, S.G. and Mossholder, K.W. (1993), "Creating readiness for organizational change", Human Relations, Vol. 46 No. 6, pp. 681-703.

Ascalon, M.E., Schleicher, D.J. and Born, M.P. (2008), "Cross-cultural social intelligence”, Cross-Cultural Management: An International Journal.

Balzer, W. and Moulines, C.U. (2011), "Structuralist theory of science: focal issues, new results”, Walter de Gruyter, Vol. 6.

Bandura, A. (2003), "Social cognitive theory for personal and social change by enabling media", In Entertainment-Education and Social Change, Routledge, pp. 97-118.

Bandura, A. and Walters, R.H. (1977), Social Learning Theory, Vol. 1, Prentice-hall, Englewood Cliffs, NJ.

Baron-Cohen, S., Ring, H.A., Wheelwright, S., Bullmore, E.T., Brammer, M.J., Simmons, A. and Williams, S.C. (1999), "Social intelligence in the normal and autistic brain: an fMRI study", European Journal of Neuroscience, Vol. 11 No. 6, pp. 1891-1898.

Barron, P. and Sharpe, J. (2005), Counting conflicts-using newspaper reports to understand violence in Indonesia.

Bollinger, A.S. and Smith, R.D. (2001), "Managing organizational knowledge as a strategic asset", Journal of Knowledge Management, Vol. 5 No. 1, pp. 8-18.

Boudreaux, C.J., Nikolaev, B.N. and Klein, P. (2019), "Socio-cognitive traits and entrepreneurship: the moderating role of economic institutions", Journal of Business Venturing, Vol. 34 No. 1, pp. 178-196.

Braithwaite, D.O. and Schrodt, P. (2014), Engaging Theories in Interpersonal Communication: Multiple Perspectives, Sage Publications.

Brown, J.S., Collins, A. and Duguid, P. (1989), "Situated cognition and the culture of learning", Educational Researcher, Vol. 18 No. 1, pp. 32-42.

Bryant, C. and Jary, D. (2014), Giddens' Theory of Structuration: A Critical Appreciation, Routledge.

Callao, M.P. and Ruisánchez, I. (2018), "An overview of multivariate qualitative methods for food fraud detection", Food Control, Vol. 86, pp. 283-293.

Cao, L., Mohan, K., Xu, P. and Ramesh, B. (2009), "A framework for adapting agile development methodologies”, European Journal of Information Systems, Vol. 18 No. 4, pp. 332-343.

Carpentier, N. and Cammaerts, B. (2006), "Hegemony, democracy, agonism, and journalism: an interview with Chantal Mouffe", Journalism Studies, Vol. 7 No. 6, pp. 964-975.

Child, J.T. and Shumate, M. (2007), "The impact of communal knowledge repositories and people-based knowledge management on perceptions of team effectiveness", Management Communication Quarterly, Vol. 21 No. 1, pp. 29-54.

Clancey, W.J. (1997), Situated Cognition: On Human Knowledge and Computer Representations, Cambridge university press.

Coleman, P.T., Kugler, K.G., Vallacher, R. and Kim, R. (2019), "Hoping for the best, preparing for the worst regulatory focus optimality in high and low-intensity conflict", INTERNATIONAL JOURNAL OF CONFLICT Management, Vol. 30 No. 1, pp. 45-64. 
Contractor, N.S. and Monge, P.R. (2002), "Managing knowledge networks", Management Communication Quarterly, Vol. 16 No. 2, pp. 249-258.

Crespy, A. and Vanheuverzwijn, P. (2019), "What "Brussels" means by structural reforms: empty signifier or constructive ambiguity?”, Comparative European Politics, Vol. 17 No. 1, pp. 92-111.

Analysis of social cognition

Creswell, J.W. and Creswell, J.D. (2017), Research Design: Qualitative, Quantitative, and Mixed Methods Approaches, Sage publications.

Cuéllar, D.P. (2018), From the Conscious Interior to an Exterior Unconscious: Lacan, Discourse Analysis, and Social Psychology, Routledge.

Del Brìo, J.A. and Junquera, B. (2003), "A review of the literature on environmental innovation management in SMEs: implications for public policies", Technovation, Vol. 23 No. 12, pp. 939-948.

DeSanctis, G. and Poole, M.S. (1994), "Capturing the complexity in advanced technology use: adaptive structuration theory”, Organization Science, Vol. 5 No. 2, pp. 121-147.

Dobson, K.S. and Khatri, N. (2000), "Cognitive therapy: looking backward, looking forward”, Journal of Clinical Psychology, Vol. 56 No. 7, pp. 907-923.

Dorr, A. (2017), "Common errors in reasoning about the future: three informal fallacies", Technological Forecasting and Social Change, Vol.116, pp. 322-330.

Earley, P.C. and Ang, S. (2003), Cultural Intelligence: Individual Interactions across Cultures, Stanford University Press.

Ernstson, H., Lawhon, M. and Duminy, J. (2014), "Conceptual vectors of African urbanism: 'engaged theory-making' and 'platforms of engagement", Regional Studies, Vol. 48 No. 9, pp. 1563-1577.

Ford, D., Myrden, S.E. and Jones, T.D. (2015a), "Understanding "disengagement from knowledge sharing": engagement theory versus adaptive cost theory", Journal of Knowledge Management, Vol. 19 No. 3.

Ford, D., Myrden, S.E. and Jones, T.D. (2015b), "Understanding “disengagement from knowledge sharing": engagement theory versus adaptive cost theory", Journal of Knowledge Management, Vol. 19 No. 3, pp. 476-496.

Furumo, K. and Melcher, A. (2006), "The importance of social structure in implementing ERP systems: a case study using adaptive structuration theory", Journal of Information Technology Case and Application Research, Vol. 8 No. 2, pp. 39-58.

Gey, S.G. (1988), "The apologetics of suppression: the regulation of pornography as act and idea", Michigan Law Review, Vol. 86 No. 7, pp. 1564-1634.

Gherardi, S. (2009), Organizational Knowledge: The Texture of Workplace Learning, John Wiley and Sons.

Giddens, A. (1991), "Structuration theory. Past, present, and future", in Bryant, C. and Jary, D. (Eds). Giddens' Theory of Structuration. A Critical Appreciation, Routledge, London.

Hair, J.F., Black, W.C., Babin, B.J., Anderson, R.E. and Tatham, R.L. (2006), Multivariate Data Analysis, Vol. 6, Pearson Prentice Hall, Upper Saddle River, NJ.

Herrmann, E., Call, J., Hernández-Lloreda, M.V., Hare, B. and Tomasello, M. (2007), "Humans have evolved specialized skills of social cognition: the cultural intelligence hypothesis", Science, Vol. 317 No. 5843, pp. 1360-1366.

Hessels, J. and Kemna, M. (2008), "Internationalization of European SMEs towards emerging markets. Scientific analysis of entrepreneurship and SMEs", Netherlands Ministry of Economic Affairs, pp. 1-17.

Hidayanto, A.N., Hasibuan, M.A., Handayani, P.W. and Sucahyo, Y.G. (2013), "Framework for measuring ERP implementation readiness in small and medium enterprise (SME): a case study in software developer company", Journal of Computers, Vol. 8 No. 7, pp. 1777-1782. 
Hsieh, H.-F. and Shannon, S.E. (2005), “Three approaches to qualitative content analysis”, Qualitative Health Research, Vol. 15 No. 9, pp. 1277-1288.

Hundleby, C. (2010), "The authority of the fallacies approach to argument evaluation", Informal Logic, Vol. 30 No. 3, p. 279.

Irjayanti, M. and Azis, A.M. (2012), "Barrier factors and potential solutions for Indonesian SMEs", Procedia Economics and Finance, Vol. 4, pp. 3-12.

Jonassen, D.H. and Rohrer-Murphy, L. (1999), "Activity theory as a framework for designing constructivist learning environments", Educational Technology Research and Development, Vol. 47 No. 1, pp. 61-79.

Kahn, W.A. (1990), "Psychological conditions of personal engagement and disengagement at work", Academy of Management Journal, Vol. 33 No. 4, pp. 692-724.

Katjasungkana, N. and Wieringa, S. (2003), "Sexual politics and reproductive rights in Indonesia", Development, Vol. 46 No. 2, pp. 63-67.

Kearsley, G. and Shneiderman, B. (1998), "Engagement theory: a framework for technology-based teaching and learning", Educational Technology, Vol. 38 No. 5, pp. 20-23.

Kebede, M., Zegeye, D.T. and Zeleke, B.M. (2017), "Predicting CD4 count changes among patients on antiretroviral treatment: application of data mining techniques", Computer Methods and Programs in Biomedicine, Vol. 152, pp. 149-157.

Kihlstrom, J.F. and Cantor, N. (1989), "Social intelligence and personality: there's room for growth", Advances in Social Cognition, Vol. 2, pp. 197-214.

Kihlstrom, J.F. and Cantor, N. (2000), "Social intelligence", Handbook of Intelligence, Vol. 2, pp. 359-379.

Kimmerle, J., Cress, U. and Held, C. (2010), "The interplay between individual and collective knowledge: technologies for organizational learning and knowledge building”, Knowledge Management Research and Practice, Vol. 8 No. 1, pp. 33-44.

Kirshner, D. and Whitson, J.A. (1997), Situated Cognition: Social, Semiotic, and Psychological Perspectives, Psychology Press.

Koslow, A. (2005), A Structuralist Theory of Logic, Cambridge University Press.

Kureshi, N., Qureshi, F. and Sajid, A. (2010), "Current health of quality management practices in service sector SME”, The TQM Journal, Vol. 22 No. 3, pp. 317-329.

Lacy, S., Watson, B.R., Riffe, D. and Lovejoy, J. (2015), "Issues and best practices in content analysis", Journalism and Mass Communication Quarterly, Vol. 92 No. 4, pp. 791-811.

Loveridge, R. (2013), “The Aston studies: a journey towards a science of administration?”, The Oxford Handbook of Management Theorists.

Magnus, P.D. and Callender, C. (2004), "Realist ennui and the base rate fallacy", Philosophy of Science, Vol. 71 No. 3, pp. 320-338.

Maier, R. and Hadrich, T. (2011), "Knowledge management systems", Encyclopedia of Knowledge Management, 2nd Ed., IGI Global, pp. 779-790.

Mikhaeil, C.A. and Baskerville, R.L. (2019), "Using semiotics to analyze representational complexity in social media", Information and Organization, Vol. 29 No. 4, p. 100271.

Nishida, T. (2001), "Social intelligence design-an overview", Paper presented at the Annual Conference of the Japanese Society for Artificial Intelligence.

O'Brien, H.L. and Toms, E.G. (2008), "What is user engagement? A conceptual framework for defining user engagement with technology", Journal of the American Society for Information Science and Technology, Vol. 59 No. 6, pp. 938-955.

Owenby, P.H. (2002), "Organizational learning communities and the dark side of the learning organization", New Directions for Adult and Continuing Education, Vol. 2002 No. 95, pp. 51-60. 
Panigrahi, R. and Borah, S. (2018), "Rank allocation to J48 group of decision tree classifiers using binary and multiclass intrusion detection datasets", Procedia Computer Science, Vol. 132, pp. 323-332.

Panjaitan, J., Darwin, M., Bastian, I. and Sukamdi, S. (2020), "What do banks, rural credit institutions, and regulators infer from the current strengths and standing of Indonesian SMEs? ", Gadjah Mada International Journal of Business, Vol. 22 No. 1, pp. 1-23.

Parker, C.M., Redmond, J. and Simpson, M. (2009), "A review of interventions to encourage SMEs to make environmental improvements", Environment and Planning C: Government and Policy, Vol. 27 No. 2, pp. 279-301.

Patil, T. and Sherekar, S.S. (2013), "Performance analysis of naive Bayes and J48 classification algorithm for data classification", International Journal of Computer Science and Applications, ISSN: 0974, 1011.

Pielke, R.A. (1999), "Nine fallacies of floods”, Climatic Change, Vol. 42 No. 2, pp. 413-438.

Pinho, C., Franco, M. and Mendes, L. (2019), "Exploring the conditions of success in e-libraries in the higher education context through the lens of the social learning theory", Information and Management, Vol. 57 No. 4, p. 103208.

Poole, M. and Desanctis, G. (1990), "Understanding the use of group decision support systems: the theory of adaptive structuration", Organizations and Communication Technology, SAGE Publications, pp. 173-193.

Proctor, K.R. and Niemeyer, R.E. (2020), "Retrofitting social learning theory with contemporary understandings of learning and memory derived from cognitive psychology and neuroscience", Journal of Criminal Justice, Vol. 66.

Puklavec, B., Oliveira, T. and Popovič, A. (2018), "Understanding the determinants of business intelligence system adoption stages", Industrial Management and Data Systems, Vol. 118 No. 1, pp. 236-261.

Pun, K.F. and Nathai-Balkissoon, M. (2011), "Integrating knowledge management into organizational learning”, The Learning Organization, Vol. 18 No. 3, pp. 203-223.

Raj, S.S. and Nandhini, M. (2018), "Ensemble human movement sequence prediction model with apriori based probability tree classifier (APTC) and bagged J48 on machine learning", Journal of King Saud University-Computer and Information Sciences, Forthcoming.

Razmerita, L., Kirchner, K. and Nabeth, T. (2014), "Social media in organizations: leveraging personal and collective knowledge processes", Journal of Organizational Computing and Electronic Commerce, Vol. 24 No. 1, pp. 74-93.

Ross, K.G. and Pierce, L.G. (2000), "Cognitive engineering of training for adaptive battlefield thinking", Paper presented at the Proceedings of the Human Factors and Ergonomics Society Annual Meeting.

Saini, D. (2013), "Model development for key enablers in the implementation of knowledge management", The IUP Journal of Knowledge Management, Vol. 11 No. 2, pp. 46-62.

Schmidt, C. (2016), "Agile software development", Agile Software Development Teams, Springer, pp. 7-35.

Scott Poole, M. and DeSanctis, G. (1992), "Microlevel structuration in computer-supported group decision making", Human Communication Research, Vol. 19 No. 1, pp. 5-49.

Seal, C.R., Boyatzis, R.E. and Bailey, J.R. (2006), "Fostering emotional and social intelligence in organizations", Organization Management Journal, Vol. 3 No. 3, pp. 190-209.

Sekaran, U. and Bougie, R. (2016), Research Methods for Business: A Skill-Building Approach, John Wiley and Sons.

Shortt, D., Hallett, F., Spendlove, D., Hardy, G. and Barton, A. (2012), "Teaching, morality, and responsibility: a structuralist analysis of a teachers' code of conduct", Teaching and Teacher Education, Vol. 28 No. 1, pp. 124-131.
Analysis of social cognition 
JEEE 13,5

Sinclaire, J.K. and Vogus, C.E. (2011), "Adoption of social networking sites: an exploratory adaptive structuration perspective for global organizations", Information Technology and Management, Vol. 12 No. 4, pp. 293-314.

Singh, R.K., Garg, S.K. and Deshmukh, S. (2010), "The competitiveness of SMEs in a globalized economy", Management Research Review, Vol. 33 No. 1, p. 54.

Sørnes, J.-O., Stephens, K.K., Browning, L.D. and Sætre, A.S. (2005), “A reflexive model of ICT practices in organizations", Informing Science: The International Journal of an Emerging Transdiscipline, Vol. 8, pp. 123-142.

Sterelny, K. (2007), "Social intelligence, human intelligence, and niche construction", Philosophical Transactions of the Royal Society B: Biological Sciences, Vol. 362 No. 1480, pp.719-730.

Stones, R. (2005), Structuration Theory, Macmillan International Higher Education.

Street, C.T. and Cameron, A.F. (2007), "External relationships and the small business: a review of small business alliance and network research", Journal of Small Business Management, Vol. 45 No. 2, pp. 239-266.

Thorndike, E.L. (1920), "Intelligence and its uses", Harper's magazine.

Trullols, E., Ruisánchez, I. and Rius, F.X. (2004), "Validation of qualitative analytical methods", TrAC Trends in Analytical Chemistry, Vol. 23 No. 2, pp. 137-145.

Tu, C.-H. (2000), "Online learning migration: from social learning theory to social presence theory in a CMC environment”, Journal of Network and Computer Applications, Vol. 23 No. 1, pp. 27-37.

van Schaik, C.P. and Burkart, J.M. (2011), "Social learning and evolution: the cultural intelligence hypothesis", Philosophical Transactions of the Royal Society B: Biological Sciences, Vol. 366 No. 1567, pp. 1008-1016.

Vernon, P.E. (1933), "Some characteristics of the good judge of personality", The Journal of Social Psychology, Vol. 4 No. 1, pp. 42-57.

Wang, S., Hung, K. and Huang, W.-J. (2019), "Motivations for entrepreneurship in the tourism and hospitality sector: a social cognitive theory perspective", International Journal of Hospitality Management, Vol. 78, pp. 78-88.

Weiner, B.J. (2009), "A theory of organizational readiness for change", Implementation Science, Vol. 4 No. 1, p. 67.

Wendt, S. and Seymour, S. (2010), “Applying post-structuralist ideas to empowerment: implications for social work education”, Social Work Education, Vol. 29 No. 6, pp. 670-682.

Whiteley, A., Price, C. and Palmer, R. (2013), “Corporate culture change: adaptive culture structuration and negotiated practice", Journal of Workplace Learning, Vol. 25 No. 7, pp. 476-498.

Witten, I.H., Frank, E. and Hall, M.A. (2011), Data Mining: Practical Machine Learning Tools and Techniques, Morgan Kaufmann Publishers.

\section{Corresponding author}

Sumiyana Sumiyana can be contacted at: sumiyana@ugm.ac.id

For instructions on how to order reprints of this article, please visit our website:

www.emeraldgrouppublishing.com/licensing/reprints.htm

Or contact us for further details: permissions@emeraldinsight.com 